\title{
Application of a Mathematical Model to the Sierra Indiana Ore Leaching Process Containing Thorium, by Means of $\mathrm{H}_{2} \mathrm{SO}_{4}$ Solution and $\mathrm{HCl}$
}

\author{
Pedro Orrego, Peter Fleming, Jorge Skeet, Ramón Ávila \\ Departamento de Materiales Avanzados, Comisión Chilena de Energía Nuclear, Santiago, Chile \\ Email: Pedro.orrego@cchen.cl, Peter.fleming@cchen.cl
}

How to cite this paper: Orrego, P., Fleming, P., Skeet, J. and Ávila, R. (2019) Application of a Mathematical Model to the Sierra Indiana Ore Leaching Process Containing Thorium, by Means of $\mathrm{H}_{2} \mathrm{SO}_{4}$ Solution and $\mathrm{HCl}$. World Journal of Nuclear Science and Technology, 9, 16-26.

https://doi.org/10.4236/winst.2019.91002

Received: October 31, 2018

Accepted: January 12, 2019

Published: January 15, 2019

Copyright $\odot 2019$ by author(s) and Scientific Research Publishing Inc. This work is licensed under the Creative Commons Attribution International License (CC BY 4.0).

http://creativecommons.org/licenses/by/4.0/

\begin{abstract}
The existence of the thorium element in the ores from the Atacama region, Chile, and its importance in the activities of the nuclear industry, have generated the interest of the Chilean Nuclear Energy Commission (CChEN) to study the technical feasibility of its recovery, like $\mathrm{ThO}_{2}$ through the implementation of hydrometallurgical techniques, such as leaching, solvent extraction, among others. The present work has become a report about the research carried out in the Extractive Metallurgy Area of the Department of Advanced Materials of CChEN, whose objective is to know the behavior of the thorium element when the mineral carrier is leached. The leaching tests were carried out in a glass reactor in batch mode, by mechanical agitation, varying different operational parameters, such as: type of leaching solution, concentration of acid in the solution, system temperature and granulometry of the mineral. The results indicate that there is technical feasibility for the recovery of thorium by leaching the mineral carrier with hydrochloric and/or sulfuric solution. The highest recovery of thorium for a sulfuric solution was $70.0 \%$ and for a hydrochloric solution of $83.8 \%$, so the process presents a good efficiency in both cases. For a hydrochloric solution, the mathematical model of the thorium recovery efficiency obtained is:
\end{abstract}

$$
\begin{aligned}
Y= & 31.14+26.25 * X_{1}+8.69 * X_{2}-0.82 * X_{3}+9.5 * X_{12} \\
& -0.83 * X_{13}-3.71 * X_{23}-1.83 * X_{123}+6.46
\end{aligned}
$$

The concentration of $\mathrm{HCl}$ and temperature, as well as their interaction, significantly affect the recovery of thorium for Sierra Indiana mineral, as well as temperature and granulometry. The previous model gives a good representativeness of $99.98 \%$. For a sulfuric solution, the mathematical model of the thorium recovery efficiency obtained is:

$$
\begin{aligned}
Y= & 29.78+25.92 * X_{1}+0.99 * X_{2}-1.05 * X_{3}-2.05 * X_{12} \\
& -9.84 * X_{13}-5.26 * X_{23}-3.87 * X_{123}+15.18
\end{aligned}
$$


The model indicates that the recovery of thorium for the mineral is significantly affected by the concentration of sulfuric acid, and to a lesser degree by the temperature and granulometry. The model provides a representativeness of $98.3 \%$.

\section{Keywords}

Thorium, Leaching, Sierra Indiana, Atacama, Chile, Metallurgy

\section{Introduction}

The thorium corresponds to a radioactive chemical element belonging to the actinides, which is highly electropositive and its main oxidation state is +4 . It is possible to find it dispersed in a large part of soils and rocks, presenting mainly as ${ }^{232} \mathrm{Th}$ and in a more concentrated form in minerals of monazite, thorite and/or torianite, reaching in the latter an average concentration of $70 \%$ [1].

In Chile, several areas with the presence of thorium have been identified through the use of geochemical, radiometric and aerospectrometric techniques and analysis. One of these zones corresponds to Sierra Indiana, located in the Atacama region, $60 \mathrm{~km}$ north of the city of Copiapó. It is formed by a sequence of volcanic rocks, from the Lavas and Brechas unit, of lower Cretaceous age, intruded by plutons of the Upper Cretaceous age, presenting lithologies from diorites to aplites [2].

The sample of treated mineral presents a rock composed of feldspars of the plagioclase type, mixed with ferromagnesians of blackish green color, associated with fibrous amphibole. It presents opaque minerals like magnetite transformed to hematite, associated with minerals included in the group of "Radioactive Complex Oxides of Fe, Ti, U, Th and REE", as can be seen in Figure 1. It also presents opaque minerals associated with systems of guides and streaks, composed by ferromagnesians. The fractionation of the ferromagnesians can give a series of minerals like ilmenite and spheno [3].

\section{Experimental Procedure and Results}

To obtain a concentrate of thorium oxide $\left(\mathrm{ThO}_{2}\right)$, from the carrier mineral from Sierra Indiana, it was proposed to study the general process reported in the diagram of Figure 2, which includes the stage of crushing and grinding the ore, in order to decrease the particle size and release the element of interest, to be subsequently leached. After the leaching stage is the application of solvent extraction process, to purify and concentrate the solution containing thorium, to subsequently implement the precipitation step obtaining a compound of this element, which will be calcined to obtain a concentrate of thorium oxide.

Then, the experimental procedure carried out to specify the tests destined to the leaching stage is reported, in order to recover the thorium element from its 
mineral matrix. These tests were carried out in the laboratories of the Extractive Metallurgy Area of the Department of Advanced Materials of the Chilean Nuclear Energy Commission (CChEN).

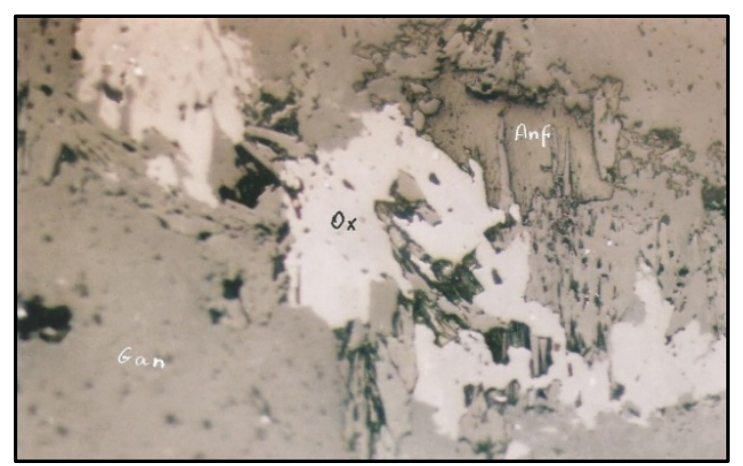

Figure 1. Polished cut. The micrograph shows mineralization of "radioactive complex oxides" [Ox] related to developing crystals of spheno type (dark color), in contact with fibrous amphibole (chrysolite or tremolite) [Anf]. The rest of the sample is bargain [Gan]. Increase $10 \times 20$. Parallel Nicoles. Scale $1 \mathrm{~cm} .=50$ microns (Boris Alarcón Farías, 2014).

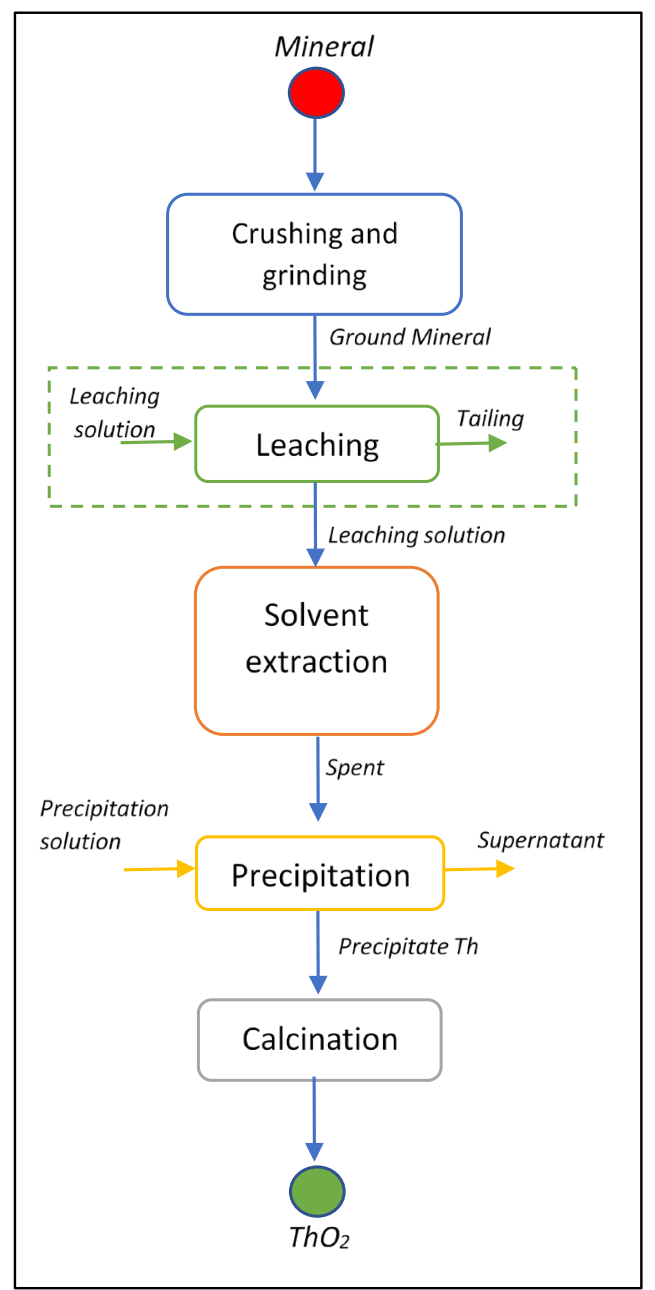

Figure 2. Thorium oxide concentrate $\left(\mathrm{ThO}_{2}\right)$ process, from Sierra Indiana ore. 


\subsection{Physical Characterization of the Mineral}

The physical characteristics of the mineral are reported in Table 1 . It was mentioned that the density was determined by the pycnometric method and natural humidity through the method described in the ASTM-D2216 standard [4].

The values obtained indicate that the mineral has a typical behavior of the ores located in the northern zone of Chile, Atacama region, which was considered to define operational parameters in the crushing and grinding stage.

\subsection{Chemical Characterization of the Mineral}

The concentration of the elements of interest present in the mineral are reported in Table 2.

This characterization has allowed to know the average grade of thorium in this mineral, which is one of the highest detected in the Atacama region. Additionally, this information is essential to theoretically know the stoichiometric consumption of acid in the leaching process and to define some values of the operational parameters. The mineral has a high percentage of elements such as iron, calcium and aluminum, considered important impurities that must be eliminated in stages after leaching process.

\subsection{Granulometric Test}

The ore samples were subjected to a process of size reduction, using a jaw crusher and a planetary mill, obtaining sizes of $100 \%-200 \%$ \# and $100 \%-60 \%$ \#, whose distribution is shown in Figure 3.

When performing a chemical characterization by size, there is evidence of an increase in the concentration of Th between meshes 20 (525 ppm) and 45 (1025 ppm), and a decrease of 73\% between meshes 100 (1078 ppm) and 140 (288.8 ppm). Its maximum point was reached with the 60 mesh, with a value of 2621 ppm of Th, then decay to a concentration of 366.6 ppm under 200 mesh, what is possible to observe in Figure 4. This distribution of thorium through the different mesh sizes does not obey a normal behavior, so it will be the subject of future research studies.

Table 1. Physical characterization of the mineral.

\begin{tabular}{cc}
\hline Parameter & Value/unit \\
\hline Mineral density & $2.84\left[\right.$ tons $\left./ \mathrm{m}^{3}\right]$ \\
Natural humidity & $0.52 \%$ \\
\hline
\end{tabular}

Table 2. Concentration of minerals present in Sierra Indiana.

\begin{tabular}{cccccc}
\hline Element & $\begin{array}{c}\mathrm{Th} \\
(\mathrm{ppm})\end{array}$ & $\mathrm{U}(\mathrm{ppm})$ & $\mathrm{REE}(\mathrm{ppm})$ & $\begin{array}{c}\mathrm{Fe} \\
(\%)\end{array}$ & $\begin{array}{c}\mathrm{Cu} \\
(\mathrm{ppm})\end{array}$ \\
\hline Conc. & 778.7 & 15.17 & 487.0 & 1.9 & 24.4 \\
Element & $\mathrm{Mo}$ & $\mathrm{Ca}$ & $\mathrm{Al}$ & $\mathrm{Ti}$ & $\mathrm{Si}$ \\
Conc. & $(\mathrm{ppm})$ & $(\%)$ & $(\%)$ & $(\mathrm{ppm})$ & $(\%)$ \\
\hline
\end{tabular}




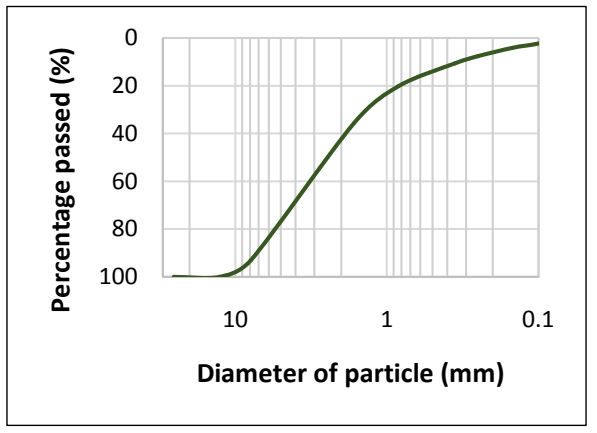

Figure 3. Granulometric curve, Sierra Indiana ore.

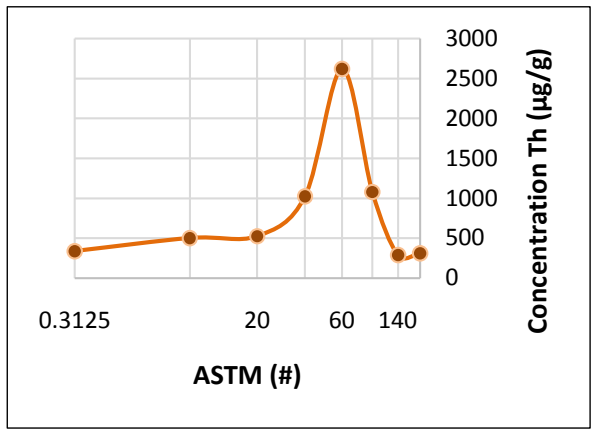

Figure 4. Th concentration by size for Sierra Indiana ore.

\subsection{ISO pH Test}

The purpose of these tests, also known as "rolled bottle leaching test", is to know the general consumption of acid, by the mineral. The implemented system corresponds to a roller agitator, where a pulp of ore was treated in bottles of $10 \mathrm{li}$ ters each one, measuring the $\mathrm{pH}$ of the solution in different time intervals, until reaching a constant value. Two solutions, corresponding to a sulfuric and hydrochloric matrix, were used separately. The results obtained indicate that, the consumptions of acid for sulfuric acid are 125.5 [ $\mathrm{kg} \mathrm{H}_{2} \mathrm{SO}_{4} /$ tonne Mineral] and $937.2\left[\mathrm{~kg} \mathrm{H}_{2} \mathrm{SO}_{4} / \mathrm{kg} \mathrm{Th}\right.$ ], for hydrochloric acid are 70.3 [ $\mathrm{kg} \mathrm{HCl} /$ tonne Mineral] and $534.2[\mathrm{~kg} \mathrm{HCl} / \mathrm{kg} \mathrm{Th}]$.

\subsection{Leaching Tests}

The leaching process consists, basically, in the partial dissolution of the elements present in the mineralogical species that constitute the carrier rock, by means of an aqueous solvent solution, that is, it allows the individual or group separation of soluble elements by means of a leaching agent, obtaining a rich solution or loaded with the element of interest and others, known as Pregnant Leach Solution (PLS).

The leaching of thorium, using a solution of hydrochloric acid, can generate the following main chemical reactions [5] [6]:

$$
\begin{gathered}
T h^{4+}+2 \mathrm{Cl}^{-} \leftrightarrow T h \mathrm{Cl}_{2}^{2+} \\
T h^{4+}+3 \mathrm{Cl}^{-} \leftrightarrow T h \mathrm{Cl}_{3}^{+}
\end{gathered}
$$




$$
\begin{gathered}
T h^{4+}+4 \mathrm{Cl}^{-} \leftrightarrow T h \mathrm{Cl}_{4(a q)} \\
T h^{4+}+5 \mathrm{Cl}^{-} \leftrightarrow T h \mathrm{Cl}_{5}^{-}
\end{gathered}
$$

In the case of a sulfuric solution, are the following chemical reactions:

$$
\begin{gathered}
T h^{4+}+\mathrm{H}_{2} \mathrm{SO}_{4} \leftrightarrow T h \mathrm{SO}_{4}^{2+}+2 \mathrm{H}^{+} \\
T h^{4+}+2 \mathrm{H}_{2} \mathrm{SO}_{4} \leftrightarrow T h\left(\mathrm{SO}_{4}\right)_{2}+4 \mathrm{H}^{+}
\end{gathered}
$$

In order to determine the best efficiency in the recovery of thorium from its mineral matrix, the following operational parameters were studied, which, in addition, significantly influence the operating costs:

- Acid concentration in leaching solution.

- System temperature.

- Granulometry.

Two sets of 11 experiences each one were carried out, according to model $2^{3}$ methodology. The tests were carried out inside a 2 liter glass reactor, by mechanical agitation, in a batch system, heated through the use of a heating plate. The leaching ratio was $(\mathrm{S} / \mathrm{L})=1$.

The procedure used was: empty the acid solution inside the reactor, turn on the agitation system (400 RPM) and heating, when reaching the required temperature the mineral is poured slowly, maintaining the system with constant agitation, for a period of 6 hours.

Once the process is finished, the pulp is filtered, in a system composed of a funnel carrying filter paper, attached to a flask connected to a vacuum pump, separating the Pregnant Leach Solution (PLS) from the tailing, which was washed with deionized water at $\mathrm{pH} 1.8$ and a ratio $(\mathrm{S} / \mathrm{L})=1$, in order to eliminate any drag of acid solution in this solid.

\subsubsection{Experimental Matrix}

The system of experiences performed obeys the procedure for obtaining a model $2^{3}$, according to Table 3 .

The following values of the variables of interest for each leaching solution were tested, Table 4 and Table 5.

\subsubsection{Recovery Efficiencies}

Table 6 shows the thorium recoveries obtained in the leaching tests with sulfuric and hydrochloric solutions.

\subsubsection{ANAVA Table and Mathematical Models}

By means of the analysis of variance it is possible to perform the analysis of the applied mathematical model, which shows the behavior of the thorium when it is leached under these conditions.

From Table 7 and Table 8, together with the Abbreviated Doolitle Method, an analysis was developed to the mathematical model, to determine the influence of the variables studied in the percentage of thorium recovered from the 
ore, by means of the leaching technique, in this case $\mathrm{X}_{1}, \mathrm{X}_{2}$ and $\mathrm{X}_{3}$ are the independent variables, corresponding to hydrochloric acid concentration, temperature and granulometry, respectively.

$$
\begin{aligned}
Y= & 31.14+26.25 * X_{1}+8.69 * X_{2}-0.82 * X_{3}+9.5 * X_{12} \\
& -0.83 * X_{13}-3.71 * X_{23}-1.83 * X_{123}+6.46
\end{aligned}
$$

When evaluating the results of the ANAVA with the Minitab program, Figure 5 , it is feasible to visualize the individual effect of the factors under study, the graph shows that by increasing both the concentration of acid and temperature, it leads to an improvement in the recovery of thorium, thus with the granulometry, which does not have significant influence.

Regarding the effect of the interaction of the studied factors, it is possible to mention that the hydrochloric concentration together with the temperature shows a positive behavior, that is, it presents an improvement in the recovery of thorium. When analyzing the influence of acid concentration and particle size, it shows a decrease in the recovery of thorium at higher concentrations of acid, the same behavior occurs with the interaction between temperature and granulometry.

In the case of sulfuric acid, Table 9 and Table 10, together with the Abbreviated Doolitle Method, the following model was developed:

$$
\begin{aligned}
Y= & 29.78+25.92 * X_{1}+0.99 * X_{2}-1.05 * X_{3}-2.05 * X_{12} \\
& -9.84 * X_{13}-5.26 * X_{23}-3.87 * X_{123}+15.18
\end{aligned}
$$

When evaluating the results of the ANAVA with the Minitab program, Figure 6 , it is feasible to visualize the individual effect of the factors under study, the graph shows that when increasing the acid concentration, it leads to an improvement in the recovery of thorium, not so with the temperature and granulometry, which has no significant influence.

Regarding the interaction of the factors studied, this does not significantly influence the recovery of thorium.

Table 3. Experimental matrix, model $2^{3}$.

\begin{tabular}{ccccc}
\hline$\# \exp$ & Design & Acid conc. & Temp. ${ }^{\circ} \mathrm{C}$ & Granul. \\
\hline 1 & I & - & - & - \\
2 & $\mathrm{~A}$ & + & - & - \\
3 & $\mathrm{~B}$ & - & + & - \\
4 & $\mathrm{AB}$ & + & + & + \\
5 & $\mathrm{C}$ & - & - & + \\
6 & $\mathrm{AC}$ & + & - & + \\
7 & $\mathrm{BC}$ & - & + & + \\
8 & $\mathrm{ABC}$ & + & + & - \\
9 & $\mathrm{~B}$ & - & + & + \\
10 & $\mathrm{AB}$ & + & + & + \\
11 & $\mathrm{C}$ & - & - & + \\
\hline
\end{tabular}


Table 4. Values of the variables tested for a sulfuric solution.

\begin{tabular}{ccc}
\hline Solution $\mathrm{H}_{2} \mathrm{SO}_{4}$ & - & + \\
Acid concentration & $0.1 \mathrm{M}$ & $3.7 \mathrm{M}$ \\
Temperature & $25^{\circ} \mathrm{C}$ & $60^{\circ} \mathrm{C}$ \\
Granulometry & $<60 \#$ & $<200 \#$ \\
\hline
\end{tabular}

Table 5. Values of the variables tested for a hydrochloric solution.

\begin{tabular}{ccc}
\hline Solution $\mathrm{HCl}$ & - & + \\
\hline Acid concentration & $2.0 \mathrm{M}$ & $7.0 \mathrm{M}$ \\
Temperature & $25^{\circ} \mathrm{C}$ & $60^{\circ} \mathrm{C}$ \\
Granulometry & $<60 \#$ & $<200 \#$ \\
\hline
\end{tabular}

Table 6. Percent recovery of Th, in sulfuric and hydrochloric leaching tests.

\begin{tabular}{ccc}
\hline \# Exp. & \% recov. $\mathrm{Th}_{2} \mathrm{SO}_{4}$ & \% recov. Th $\mathrm{HCl}$ \\
\hline 1 & 2.1 & 3.8 \\
2 & 48.7 & 35.3 \\
3 & 5.1 & 5.8 \\
4 & 70.0 & 81.7 \\
5 & 5.5 & 8.3 \\
6 & 64.9 & 43.1 \\
7 & 2.8 & 2.2 \\
8 & 47.8 & 68.4 \\
9 & 5.4 & 6.1 \\
10 & 66.2 & 83.8 \\
11 & 5.1 & 6.9 \\
\hline
\end{tabular}

Table 7. ANAVA. Leaching solution $\mathrm{HCl}$, Part 1.

\begin{tabular}{cccc}
\hline Source of variation & Sum of squares & Degrees of freedom & Middle square \\
\hline$\sum \mathrm{Y}_{\mathrm{i}}^{2}$ & $21,686.22$ & 11 & 1971.47 \\
Because $\mathrm{X}_{0}$ & $10,845.56$ & 1 & $10,845.56$ \\
Because $\mathrm{X}_{1}$ & 8843.30 & 1 & 8843.30 \\
Because $\mathrm{X}_{2}$ & 719.32 & 1 & 719.32 \\
Because $\mathrm{X}_{3}$ & 0.52 & 1 & 0.52 \\
Because $\mathrm{X}_{12}$ & 1100.28 & 1 & 1100.28 \\
Because $\mathrm{X}_{13}$ & 14.83 & 1 & 14.83 \\
Because $\mathrm{X}_{23}$ & 126.38 & 1 & 126.38 \\
Because $\mathrm{X}_{123}$ & 32.79 & 1 & 32.79 \\
Residual sum of squares & 3.23 & 3 & 1.08 \\
Mismatches & -3.23 & 1 & -3.23 \\
Experimental error & 6.46 & 2 & 3.23 \\
\hline
\end{tabular}


Table 8. ANAVA. Leaching solution $\mathrm{HCl}$, Part 2.

\begin{tabular}{cccc}
\hline Source of variation & $\mathrm{F}$ & $\mathrm{Fa}_{0.05}$ & $\mathrm{Fo}_{0.01}$ \\
\hline Because $\mathrm{X}_{1}$ & 2737.86 & 18.5 & 98.5 \\
Because $\mathrm{X}_{2}$ & 222.7 & 18.5 & 98.5 \\
Because $\mathrm{X}_{3}$ & 0.16 & 18.5 & 98.5 \\
Because $\mathrm{X}_{12}$ & 340.64 & 18.5 & 98.5 \\
Because $\mathrm{X}_{13}$ & 4.59 & 18.5 & 98.5 \\
Because $\mathrm{X}_{23}$ & 39.13 & 18.5 & 98.5 \\
Because $\mathrm{X}_{123}$ & 10.15 & 18.5 & 98.5 \\
Residual sum of squares & 0.33 & 18.5 & 98.5 \\
Mismatches & -1 & 18.5 & 98.5 \\
$\mathrm{R}^{2}$ (\%) & & & 99.98 \\
\hline
\end{tabular}

Table 9. ANAVA. Leaching solution $\mathrm{H}_{2} \mathrm{SO}_{4}$ Part 1.

\begin{tabular}{cccc}
\hline Source of variation & Sum of squares & Degrees of freedom & Middle square \\
\hline$\Sigma \mathrm{Y}_{\mathrm{i}}^{2}$ & $18,256.86$ & 11 & 1659.71 \\
Because $\mathrm{X}_{0}$ & 9628.53 & 1 & 9506.54 \\
Because $\mathrm{X}_{1}$ & 7799.50 & 1 & 8300.35 \\
Because $\mathrm{X}_{2}$ & 11.55 & 1 & 12.52 \\
Because $\mathrm{X}_{3}$ & 9.59 & 1 & 8.21 \\
Because $\mathrm{X}_{12}$ & -25.36 & 1 & 14.47 \\
Because $\mathrm{X}_{13}$ & 122.58 & 1 & 15.57 \\
Because $\mathrm{X}_{23}$ & 259.01 & 1 & 244.38 \\
Because $\mathrm{X}_{123}$ & 147.22 & 1 & 147.22 \\
Residual sum of squares & 304.25 & 3 & 101.42 \\
Mismatches & 289.07 & 1 & 289.07 \\
Experimental error & 15.18 & 2 & 7.59 \\
\hline
\end{tabular}

Table 10. ANAVA. Leaching solution $\mathrm{H}_{2} \mathrm{SO}_{4}$ Part 2.

\begin{tabular}{cccc}
\hline Source of variation & $\mathrm{F}$ & $\mathrm{Fa}_{0.05}$ & $\mathrm{Fa}_{0.01}$ \\
\hline Because $\mathrm{X}_{1}$ & 28.71 & 18.5 & 98.5 \\
Because $\mathrm{X}_{2}$ & 0.04 & 18.5 & 98.5 \\
Because $\mathrm{X}_{3}$ & 0.03 & 18.5 & 98.5 \\
Because $\mathrm{X}_{12}$ & 0.05 & 18.5 & 98.5 \\
Because $\mathrm{X}_{13}$ & 0.05 & 18.5 & 98.5 \\
Because $\mathrm{X}_{23}$ & 0.85 & 18.5 & 98.5 \\
Because $\mathrm{X}_{123}$ & 0.51 & 18.5 & 98.5 \\
Residual sum of squares & 0.35 & 18.5 & 98.5 \\
Mismatches & 1 & 18.5 & 98.5 \\
$\mathrm{R}^{2}(\%)$ & & & 98.3 \\
\hline
\end{tabular}




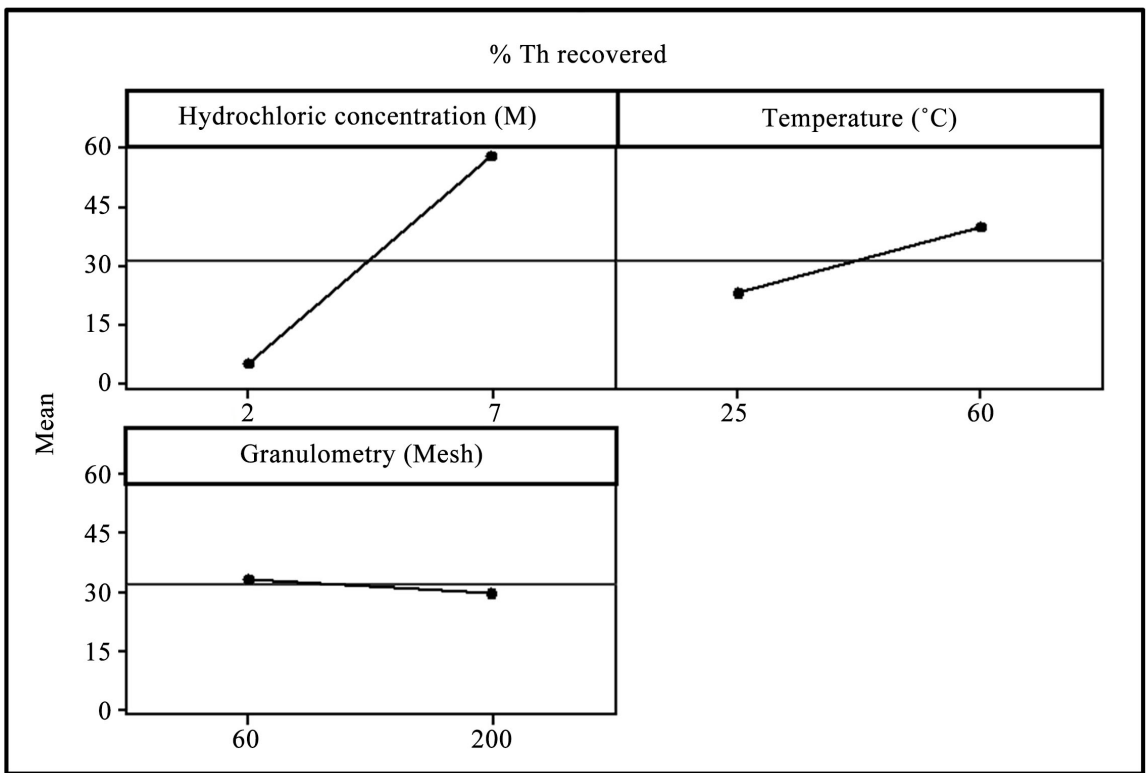

Figure 5. Individual effects of the factors under study in the recovery of Th, by leaching with $\mathrm{HCl}$ from Sierra Indiana ore.

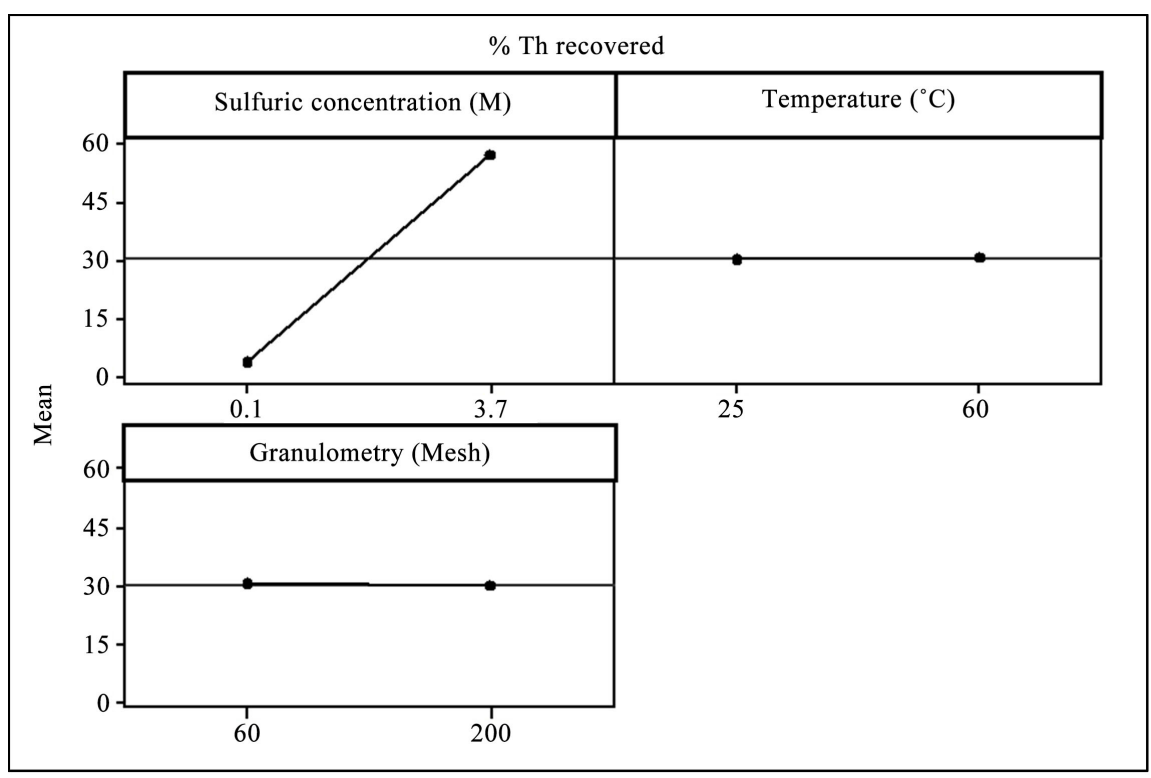

Figure 6. Individual effects of the factors under study in the recovery of Th, by leaching with $\mathrm{H}_{2} \mathrm{SO}_{4}$ from Sierra Indiana ore.

\section{Conclusions}

\subsection{Leaching}

- It is technically feasible to recover thorium by leaching the mineral carrier, with hydrochloric and/or sulfuric solution.

- The highest recovery of thorium for a sulfuric solution was $70.0 \%$ and for a hydrochloric solution of $83.8 \%$, so the process presents a good efficiency in both cases. 


\subsection{Model}

- For a hydrochloric solution, the thorium recovery efficiency model obtained gives $99.98 \%$ representativeness and corresponds to:

$$
\begin{aligned}
Y= & 31.14+26.25 * X_{1}+8.69 * X_{2}-0.82 * X_{3}+9.5 * X_{12} \\
& -0.83 * X_{13}-3.71 * X_{23}-1.83 * X_{123}+6.46
\end{aligned}
$$

- The concentration of $\mathrm{HCl}$ and temperature, as well as their interaction, significantly affect the recovery of thorium for Sierra Indiana mineral, as well as temperature and granulometry.

- For a sulfuric solution, the thorium recovery efficiency model obtained represents $98.3 \%$ representativeness and corresponds to:

$$
\begin{aligned}
Y= & 29.78+25.92 * X_{1}+0.99 * X_{2}-1.05 * X_{3}-2.05 * X_{12} \\
& -9.84 * X_{13}-5.26 * X_{23}-3.87 * X_{123}+15.18
\end{aligned}
$$

- The model indicates that the recovery of thorium for the mineral is significantly affected by the concentration of sulfuric acid, and to a lesser degree by the temperature and granulometry.

\section{Conflicts of Interest}

The authors declare no conflicts of interest regarding the publication of this paper.

\section{References}

[1] Wickleder, M.S. (2006) The Chemistry of the Actinide and Transactinide Elements. 52-160.

[2] Fortín, H. (2002) Sector Mina Santo Domingo-Mina Atacama, investigación geológica preliminar por tierras raras y uranio.

[3] Alarcón, B. (2014) Estudio macroscópico petro-calcográfico de muestras pulidas "Sierra Indiana; Quebrada del Desierto y Carmen Norte" CCHEN.

[4] Norma ASTM-D2216 (2006) Standard Test Methods for Laboratory Determination of Water (Moisture) Content of Soil and Rock by Mass.

[5] Sapsford, D.J., et al. (2012) Factors Influencing the Release Rate of Uranium, Thorium, Yttrium and Rare Earth from A Low Grade Ore. Minerals Engineering, 39, 165-172. https://doi.org/10.1016/j.mineng.2012.08.002

[6] Rand, M., et al. (2007) Chemical Thermodynamics of Thorium-Volume 11. 226-244, 267-299. 